\title{
Distribution of allergy in a population sample residing in Tucson, Arizona
}

\author{
MARTHA G CLINE, BENJAMIN BURROWS \\ From the Division of Respiratory Sciences, University of Arizona College of Medicine, Tucson, Arizona, USA
}

In this report we look at the distribution of two indices of allergy in the general population-namely, allergy skin test reactivity to a battery of common aeroallergens and the level of serum immunoglobulin $E$ (IgE). Allergy skin tests have been the standard method for identifying the allergic individual. IgE, the major antibody responsible for the immediate type of immune response, was first identified by Ishizaka ${ }^{1}$ and Johansson et $a l^{2}{ }^{2}$ and the level of serum $\operatorname{IgE}$ is sometimes used now to assess overall allergic state rather than skin test reactivity. This report will focus on the distribution of skin test reactivity and serum IgE concentrations in a general population sample, including a description of their relation to each other as well as to age, sex, and smoking history.

The data are derived primarily from the Tucson epidemiological study of airway obstructive diseases, a longitudinal study of a stratified random sample of white, non-Mexican-American households in Tucson, Arizona. The study population was enrolled initially in 1971-2. Details of the selection of the study population and general methods have been reported. ${ }^{3}$ This report represents in large part a consolidation of data that have been previously published, ${ }^{4-11}$ though some of the data have been reanalysed to allow a more consistent presentation.

Allergy skin tests were carried out on 3136 subjects aged three years or more at the time of enrolment. Five skin test solutions (house dust 1:10, Bermuda grass 1:20, tree mix 1:20, weed mix 1:20, and Dematiaceae mould mix 1:100) plus a 50\% glycerin solution control were applied by the prick technique. The tree mix consisted of Fremont cottonwood, olive, white mulberry, and mesquite. Rabbit bush, Salt bush,

\footnotetext{
Address for reprint requests: Dr Benjamin Burrows, Division of Respiratory Sciences, University of Arizona College of Medicine, Tucson, Arizona 85724, USA.
}

Russian thistle, desert ragweed, and slender ragweed were the components of the weed mix. The contents of the Dematiaceae mould mix were Alternaria, Curvularia, Helminthosporium, Cladosporium, Spondylocladium, and Stemphylium species. The weal response was measured as the sum of the longest and the shortest weal diameter. The size of the control weal was subtracted in the few cases where there was a reaction to the control solution. In 1333 of the subjects tests were repeated eight years later along with a histamine prick test.

In previous reports we have expressed skin test reactivity in terms of an index based on the frequency with which various sized reactions to each of the tests were observed in our population ${ }^{5}$-an index that is obviously specific to our series. In the present report we have expressed overall skin test reactivity as the sum of the diameters of all the weals after subtracting the control diameter from each skin test result.

Serum IgE levels were measured (M Halonen) in 2722 subjects aged 6 years or more on enrolment by the PRIST method. The mean of duplicate test results is reported in terms of international units per millilitre (IU). Values as low as $0 \cdot 1$ IU are detectable with this technique. In 1190 of the subjects the test was repeated eight years later. As noted in an earlier report, some subjects lack enrolment IgE values as their serum was used up in the other tests; there is no evidence to suggest that those whose serum IgE levels are available are not a representative group. ${ }^{7}$

Serum IgE data are also available for infants enrolled in the Tucson children's respiratory study, which began in $1980,{ }^{12}$ though they have been reported only in abstract form. ${ }^{13}$ IgE was measured in umbilical cord blood at birth and again at 6-11 (mean 9.1) months in 611 of the infants. When cord blood contained no measurable IgE in duplicate tests serum $\mathrm{IgE}$ is classified as undetectable; those with minimally detectable IgE in only one of the duplicate tests are classified as being below $0 \cdot 1 \mathrm{IU}$. 


\section{Allergy skin test reactivity}

Among subjects aged 3 or more, $36 \cdot 2 \%$ were reactive to allergy skin tests (atopic) at the time of the initial survey. In this report the term atopy is used to indicate reactivity to one or more of the aeroallergens in our skin test battery. In the Tucson area, which is in the desert in the south west of the United States, Dermatophagoides farinae is not prevalent in house dust. Reactions to house dust were relatively infrequent in our study, compared with reactions to Bermuda grass or a mix of local weeds (table 1). During a subsequent survey $D$ farinae antigen was used in addition to house dust; there were even fewer reactions to $D$ farinae than to the crude house dust antigen. ${ }^{6}$

Subjects showing skin reactivity tended to respond to more than one test. Only $16 \%$ of the subjects who showed no reaction to Bermuda grass reacted to anything else, compared with $90 \%$ of those showing a strong reaction to the Bermuda antigen $(15 \mathrm{~mm}$ or more). The size distribution of the weals produced by any given antigen tended to be Gaussian and was distinct from the bimodal distribution of large numbers of negative reactions, suggesting that reactors were a distinctive subpopulation. ${ }^{4}$

There was no relation between results of skin tests and gender (35.9\% positive in men, $36.4 \%$ positive in women), but both the frequency and the size of positive reactions were strongly related to age, with increasing reactivity during childhood and a fall in reactivity in later adult life. Overall reactivity, determined by the sum of weal sizes, tended to reach its peak between 20 and 45 years of age (fig 1).

These cross sectional observations were confirmed by longitudinal studies. ${ }^{10}$ Table 2 shows the conversion and reversion rates for change in skin test reactivity over the eight years between the two tests, both for any change and for a change of $5 \mathrm{~mm}$ or more. There was a high rate of conversion from negative to positive responses but no reversions from positive to negative in subjects aged less than 15 years on entry. In contrast, there were high reversion and relatively low conversion rates in subjects aged 55 or more over the eight years. In young to middle aged adults both conversions and reversions were relatively common. Thus the slow rate of decline in allergen skin reactivity

Table 1 Percentage of subjects with positive responses to allergy skin tests

\begin{tabular}{lr}
\hline Mould mix & $8 \cdot 2$ \\
House dust & $9 \cdot 2$ \\
Tree mix & $17 \cdot 3$ \\
Weed mix & $21 \cdot 6$ \\
Bermuda grass & $23 \cdot 9$ \\
Any positive test & $36 \cdot 2$ \\
\hline
\end{tabular}

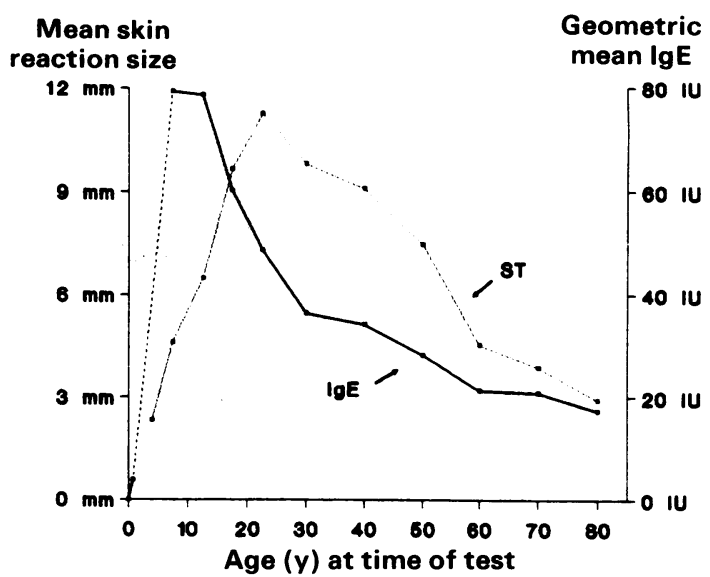

Fig 1 Allergy skin test $(S T)$ reactivity, expressed as the average sum of the smallest and largest diameter reaction to five allergy skin tests $(n=3136)$, and geometric mean $\operatorname{Ig} E$ levels ( $n=2699$ ) shown by age groups for subjects in the Tucson epidemiological study of airways obstructive diseases. The mean serum IgE level shown for the youngest age group $(n=611)$ is from the nine month data provided from the Tucson childen's respiratory study. There are currently no Tucson data available for skin tests under the age of 3 or for serum IgE values for children between 9 months and 6 years of age.

over this age span does not reflect the extent to which individual subjects are changing their atopic state.

\section{Serum IgE levels}

Except in the newborn, serum IgE levels showed an almost perfect Gaussian distribution when expressed in logarithmic form ${ }^{78}$ (fig 2). They are therefore discussed in terms of their log values or geometric means and are grouped by multiples of IgE level.

About one third of newborn infants had no detectable IgE in their cord blood and less than $5 \%$ had more than 1 international unit; the median IgE level at birth was below $0 \cdot 1 \mathrm{IU}$. By nine months of age the geometric mean IgE level had increased to $3.8 \mathrm{IU}$.

Wittig and coworkers ${ }^{14}$ have published data on

Table 2 Percentage of subjects showing a change in skin test reactivity* over eight years

\begin{tabular}{lllll}
\hline Age $(y)$ & - to + & + to & $\begin{array}{l}\text { to } \\
\geqslant 5 \mathrm{~mm}\end{array}$ & $\begin{array}{l}\geqslant 5 \mathrm{~mm} \\
\text { to }-\end{array}$ \\
\hline $6-14$ & 31.6 & 0.0 & 24.2 & 0.0 \\
$15-34$ & 36.7 & 8.2 & 26.6 & 7.0 \\
$35-54$ & 31.3 & 13.2 & 24.7 & 11.7 \\
$55-74$ & 19.3 & 22.1 & 12.5 & 20.0 \\
$\geqslant 75$ & 12.9 & 22.2 & 6.5 & 22.2 \\
\hline
\end{tabular}

*-indicates a negative response, + a positive response, and $\geqslant 5 \mathrm{~mm}$ the size of skin reactions. 


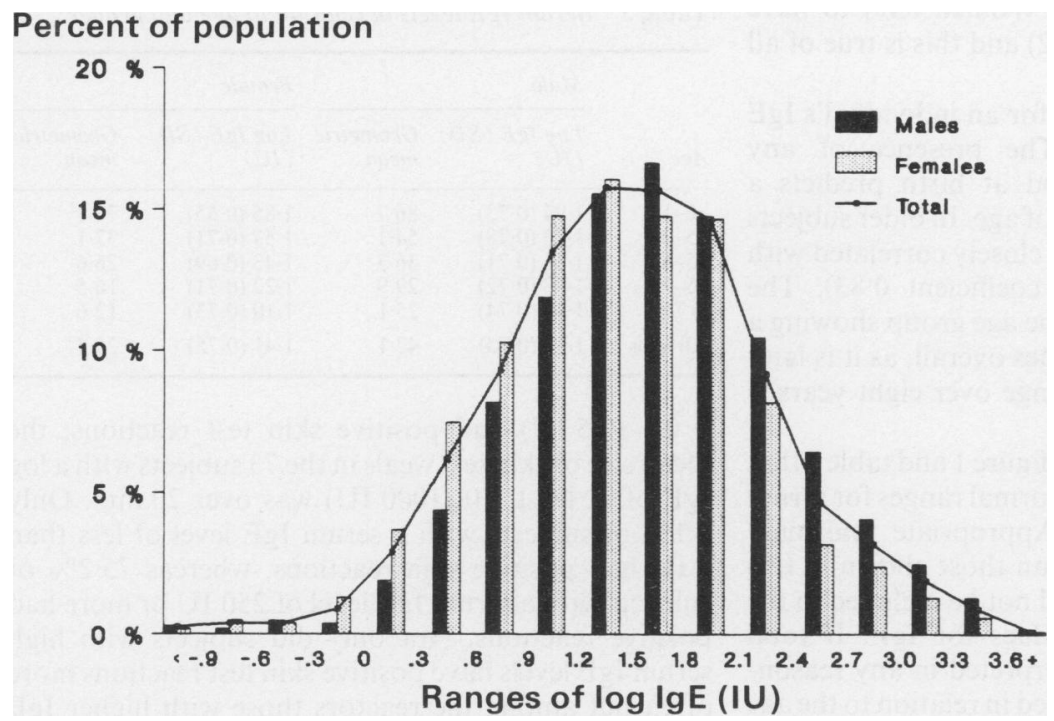

Fig 2 The distribution of serum IgE levels in 1233 males and 1489 females age 6 or more who had serum IgE levels measured on enrolment in the Tucson study of airways obstructive diseases.

children over the age of 1 year, but their series was restricted to subjects without asthma or allergic rhinitis. If we restrict our own data in the same way, the results are remarkably similar to those of Wittig $e t$ $a l$ where the age groups overlap. The data sets have been combined in figure 3 so that the change in $\operatorname{IgE}$ from birth to young adult life may be seen.

Serum IgE concentrations tend to peak around the age of 8-12 years, after which geometric mean levels decline rapidly over the next few decades, and then more gradually throughout adult life. These figures include subjects aged 6-11 months from our children's respiratory study and aged 6 years and over from our general population study.

These cross sectional observations are confirmed by our longitudinal studies covering eight years. "There was a substantial decline in IgE levels in individuals first studied when they were less than 15 years of age, a lesser but still significant decline in subjects aged 15-34 in the initial study, but no significant change over the eight years in subjects aged $\mathbf{3 5}$ or more on enrolment. The cross sectional data shown in figure 1 indicate that there is a very slow decline in IgE levels even after the age of 35 , although this decline is probably too slow to

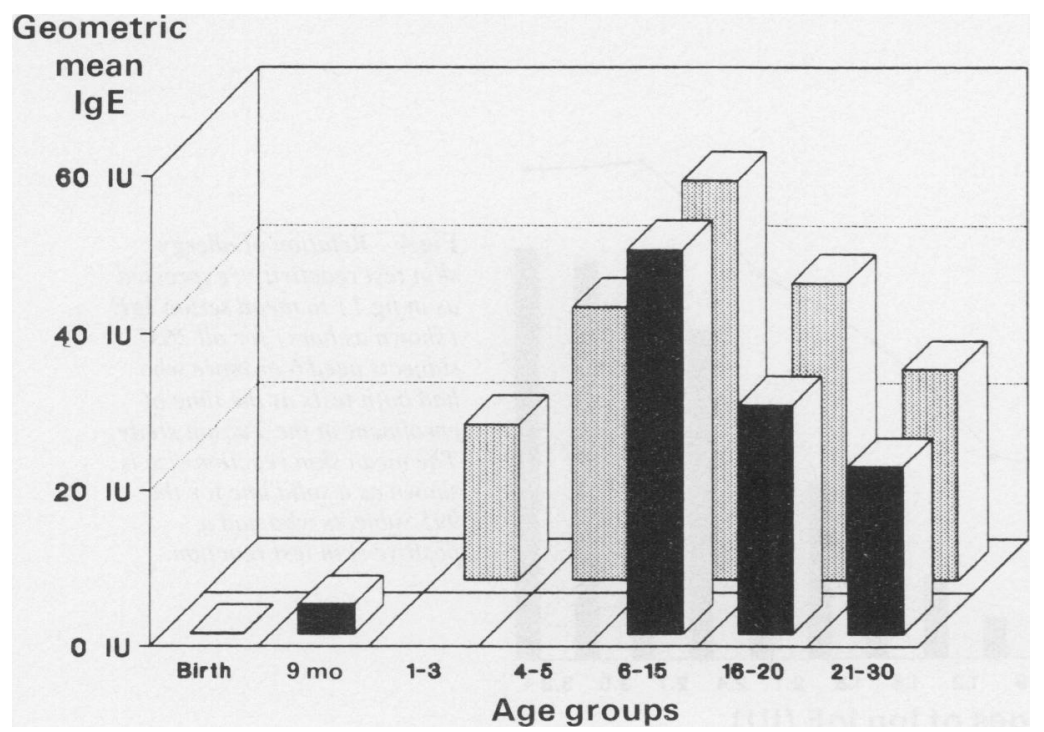

Fig 3 Data of Wittig et al ${ }^{14}$ (hatched bars) combined with those from the Tucson studies (solid bars) to display the rise in serum IgE levels from birth to their peak around the age of 8-12 and the subsequent decline by the third decade of life. The data are for subjects who deny asthma and allergic rhinitis; the geometric mean serum IgE levels for subjects aged 6 or more are therefore lower than in figure 1 , which includes all subjects in the Tucson study. 
be observed over eight years. Women tend to have lower IgE levels than men (fig 2) and this is true of all age groups (table 3 ).

There is a striking tendency for an individual's IgE level to track over time. The presence of any measurable IgE in cord blood at birth predicts a relatively high $\mathrm{IgE}$ at 9 months of age. In older subjects the IgE level eight years later is closely correlated with the initial value (correlation coefficient 0.83 ). The correlation is equally close in the age group showing a significant decline in mean values overall, as it is later in life, when the observed change over eight years is insignificant.

It is also apparent from both figure 1 and table 3 that most currently recommended normal ranges for serum IgE levels are not realistic. Appropriate "normal" values would be even lower than those shown in this paper as allergic subjects would not be included in the determination of reference values for IgE. If total serum IgE levels are to be interpreted in any reasonable way, they must be considered in relation to the age and sex of the individual. In view of the strong tendency for serum IgE levels to track with age, a relatively low serum IgE in an elderly subject may indicate a relatively high level earlier in life, when many allergic diseases begin.

\section{Interrelation of atopy and $\operatorname{IgE}$}

As would be expected, there is a very close overall correlation between serum IgE levels and skin test reactivity to allergens. As shown in figure 4 , none of the 29 subjects with a log serum IgE level of less than
Table 3 Serum IgE levels in relation to age and gender

\begin{tabular}{|c|c|c|c|c|}
\hline \multirow[b]{2}{*}{ Age (y) } & \multicolumn{2}{|l|}{ Male } & \multicolumn{2}{|l|}{ Female } \\
\hline & $\begin{array}{l}\log \lg E(S D) \\
(I U)\end{array}$ & $\begin{array}{l}\text { Geometric } \\
\text { mean }\end{array}$ & $\begin{array}{l}\log \operatorname{Ig} E(S D) \\
(I U)\end{array}$ & $\begin{array}{l}\text { Geometric } \\
\text { mean }\end{array}$ \\
\hline $6-14$ & $1.94(0.73)$ & $86 \cdot 7$ & $1.85(0.65)$ & $71 \cdot 1$ \\
\hline $15-34$ & $1.73(0.78)$ & $54 \cdot 1$ & $1.57(0.71)$ & $37 \cdot 1$ \\
\hline $35-54$ & $1.56(0.71)$ & $36 \cdot 3$ & $1.43(0.69)$ & $26 \cdot 6$ \\
\hline $55-74$ & $1.48(0.72)$ & $29 \cdot 9$ & $1.22(0.71)$ & $16 \cdot 5$ \\
\hline$\geqslant 75$ & $1.40(0.74)$ & $25 \cdot 1$ & $1.10(0.73)$ & 12.6 \\
\hline All ages & $1.51(0.75)$ & $42 \cdot 1$ & $1.41(0.75)$ & $25 \cdot 5$ \\
\hline
\end{tabular}

$-0.3(0.5 \mathrm{IU})$ had positive skin test reactions; the mean size of skin test weals in the 73 subjects with a log IgE of at least $3.0(1000 \mathrm{IU})$ was over $20 \mathrm{~mm}$. Only $8.1 \%$ of subjects with a serum IgE level of less than 4 IU had positive skin reactions, whereas $75.2 \%$ of subjects with a serum IgE level of $250 \mathrm{IU}$ or more had positive reactions. Not only did subjects with high serum IgE levels have positive skin test reactions more often but among the reactors those with higher IgE levels had larger weals.

The relation between atopy and $\operatorname{IgE}$ changes with age, however. The low rates of atopy in children obviously cannot be explained by their IgE levels, which tend to peak during childhood. The percentage of children reacting to the histamine skin test was about half of the percentage of adults who reacted. The size of the skin response to histamine is also very small in young children and increases with age. ${ }^{69} \mathrm{It}$ is not clear to what extent the low skin reactivity to histamine might explain the low rates of reactivity to common aeroallergens seen in childhood.

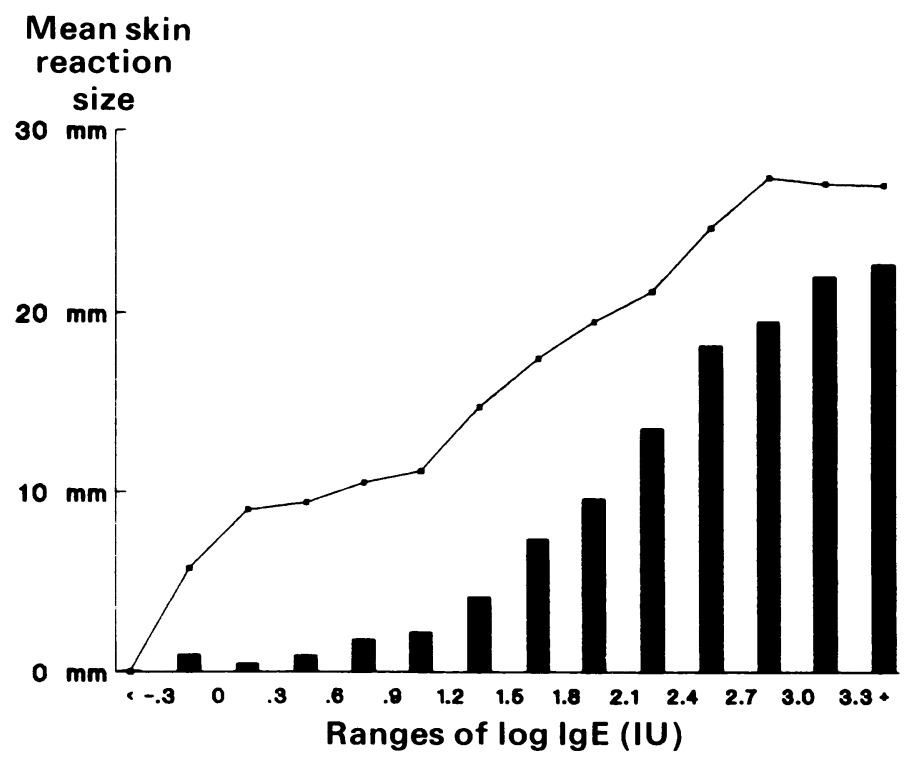

Fig 4 Relation of allergy skin test reactivity (expressed as in fig l) to mean serum $\lg E$ ( shown as hars) for all 2657 subjects aged 6 or more who had both tests at the time of enrolment in the Tucson study. The mean skin reaction size is shown as a solid line for the 995 subjects who had a positive skin test reaction. 
Although some of the decline in atopy with age may be accounted for by a fall in IgE among the elderly, this is not the entire explanation. Even within relatively narrow ranges of IgE, both children and elderly subjects tend to show less allergy skin test reactivity than young adults.

\section{Effects of smoking on atopy and serum IgE levels}

The effects of smoking on atopy and serum IgE levels are of special interest. Atopy rates tend to be lower among current smokers than either ex-smokers or never smokers (table 4) and the differences become increasingly more apparent with age. ${ }^{58}$ This appears to reflect a tendency for atopic subjects not to start smoking and to give it up if they do begin. The apparent tendency for selective smoking by nonatopic subjects would tend to obscure any tendency of smoking to increase reactivity to allergy skin tests, as has been observed in some occupational settings. ${ }^{15}$

In contrast to reactivity to allergy skin tests, serum IgE is raised in both current smokers ${ }^{8}$ and ex-smokers (table 4). Even though IgE declines with age in subjects who have smoked, it falls less than in never smokers. This is particularly true among atopic subjects. The higher rates of smoking in men accounts in part for their higher IgE levels, but men show consistently higher IgE levels than women regardless of their smoking habits (fig 5). Whether this is a direct effect of gender or reflects the exposure of men to a wider variety of antigens, such as those in occupational settings, remains a matter for speculation.

The relation between IgE and atopy is strongly affected by smoking. For any given level of $\operatorname{IgE}$

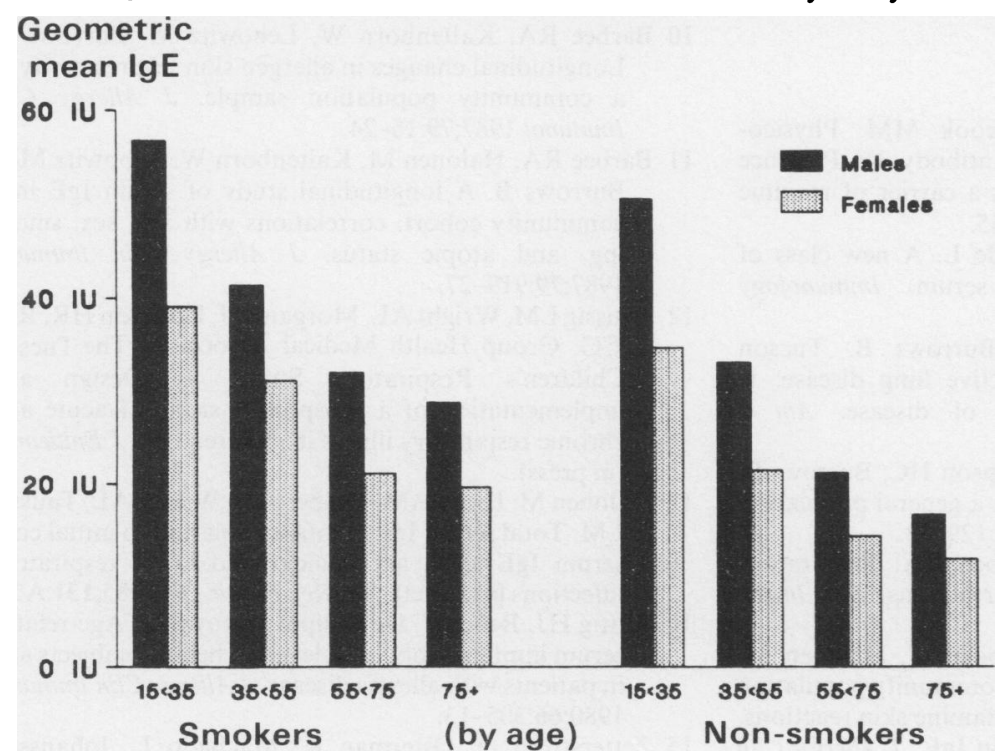

Table 4 Skin test (ST) reactivity and serum IgE levels by smoking history and age

\begin{tabular}{|c|c|c|c|c|}
\hline Age (y) & $n$ & $\begin{array}{l}\text { ST positive } \\
(\%)\end{array}$ & $\begin{array}{l}\text { Mean sum of weal } \\
\text { diameters ( } \mathrm{mm})\end{array}$ & $\begin{array}{l}\text { Geometric mean } \\
\text { IgE }(I U)\end{array}$ \\
\hline $\begin{array}{c}\text { SMOKERS } \\
15-34 \\
35-54 \\
55-74 \\
\geqslant 75\end{array}$ & $\begin{array}{r}310 \\
241 \\
214 \\
23\end{array}$ & $\begin{array}{r}45 \cdot 5 \\
33 \cdot 6 \\
17.8 \\
8.7\end{array}$ & $\begin{array}{l}8 \cdot 8 \\
5 \cdot 9 \\
2 \cdot 5 \\
2 \cdot 1\end{array}$ & $\begin{array}{l}46 \cdot 5 \\
35 \cdot 8 \\
25 \cdot 8 \\
23 \cdot 7\end{array}$ \\
\hline $\begin{array}{c}\text { EX-SMOKER } \\
15-34 \\
35-54 \\
55-74 \\
\geqslant 75\end{array}$ & $\begin{array}{r}127 \\
134 \\
250 \\
60\end{array}$ & $\begin{array}{l}53 \cdot 3 \\
50 \cdot 7 \\
28 \cdot 8 \\
15 \cdot 0\end{array}$ & $\begin{array}{r}11 \cdot 4 \\
8 \cdot 3 \\
5 \cdot 4 \\
3 \cdot 4\end{array}$ & $\begin{array}{l}50 \cdot 0 \\
28 \cdot 8 \\
27 \cdot 2 \\
22 \cdot 2\end{array}$ \\
\hline $\begin{array}{c}\text { NEVER SMO } \\
15-34 \\
35-54 \\
55-74 \\
\geqslant 75\end{array}$ & $\begin{array}{r}\text { KERS } \\
409 \\
169 \\
374 \\
107\end{array}$ & $\begin{array}{l}51 \cdot 1 \\
49.1 \\
28.9 \\
21.5\end{array}$ & $\begin{array}{r}10.8 \\
10.6 \\
5.0 \\
3.2\end{array}$ & $\begin{array}{l}40 \cdot 9 \\
24 \cdot 1 \\
15 \cdot 5 \\
12 \cdot 7\end{array}$ \\
\hline
\end{tabular}

smokers have considerably less reactivity to allergy skin tests than non-smokers (fig 6). This raises a question about the nature of the IgE in smokers. As skin test reactivity is low even though serum IgE levels are high in smokers, smoking does not appear simply to amplify the IgE response to common aeroallergens. The findings suggest that allergic stimuli other than the common aeroallergens used in this study may be important in explaining a smoker's total IgE level. Thus our usual definition of atopy, which depends on the presence of skin test reactions to common aeroallergens, may not be an accurate reflection of the overall allergic state of an individual. Clearly, there are widely varying allergens of possible clinical relevance that would not normally be included in any skin test battery. They include the many found in occupational
Fig 5 Relation of smoking to serum IgE by age and sex for the 752 male and 1132 female current and never smokers aged 15 or more at enrolment. 


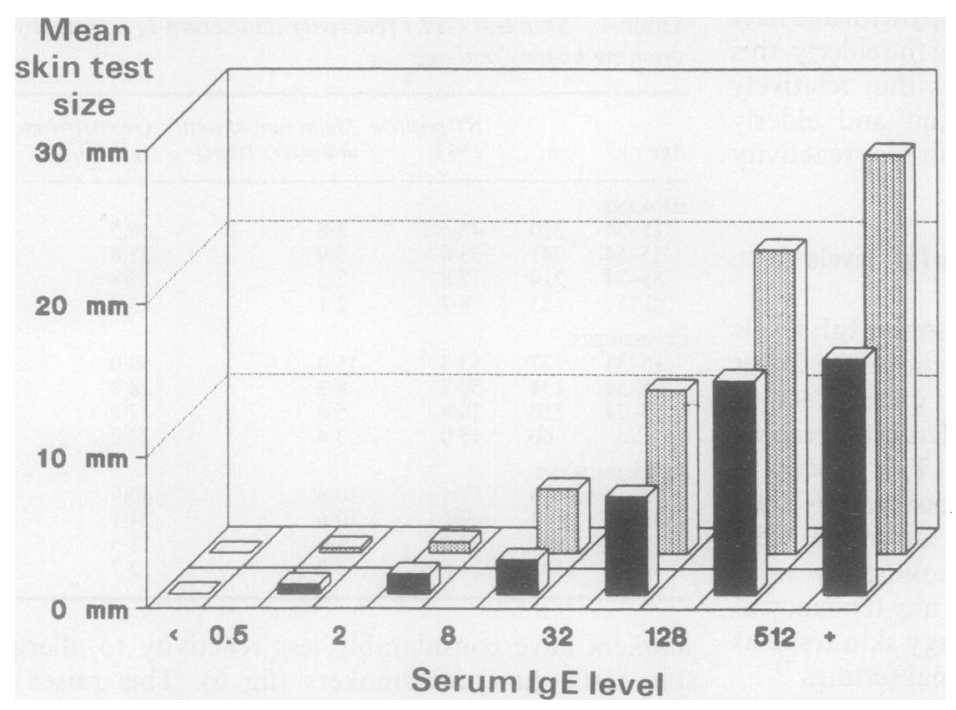

Fig 6 Relation of allergy skin test reactivity to serum IgE levels for 788 smokers (solid bars) and 1059 never smokers (hatched bars) aged 15 or more who had both tests at the time of their enrolment.

settings that mediate their effect through $\operatorname{IgE},{ }^{16} \mathrm{a}$ wide range of indoor allergens, ${ }^{17}$ and even antigens of insect origin. ${ }^{18}$ Before we use IgE levels to assess allergic states, better reference values need to be developed, which account fully for age and sex; even then the very wide range of total IgE levels will probably limit their clinical value.

This work has been supported by a specialised center of research grant from the National Heart, Lung, and Blood Institute (HL14136).

\section{References}

1 Ishizaka $\mathrm{K}$, Ishizaka T, Hornbrook MM. Physicochemical properties of reaginic antibody. IV. Presence of a unique immunoglobulin as a carrier of reaginic activity. J Immunol 1966;97:75-85.

2 Johansson SGO, Bennich H, Wide L. A new class of immunoglobulins in human serum. Immunology 1968;14:265-72.

3 Lebowitz MD, Knudson RJ, Burrows B. Tucson epidemiologic study of obstructive lung disease: 1 . Methodology and prevalence of disease. Am J Epidemiol 1975;102:137-52.

4 Barbee RA, Lebowitz MD, Thompson HC, Burrows B. Immediate skin-test reactivity in a general population sample. Ann Intern Med 1976;84:129-33.

5 Burrows B, Lebowitz MD, Barbee RA. Respiratory disorders and allergy skin-test reactions. Ann Intern Med 1976;84:134-9.

6 Barbee RA, Brown WG, Kaltenborn W, Halonen M. Allergen skin test reactivity in a community population sample: correlation with age, histamine skin reactions, and total serum immunoglobulin IgE. J Allergy Clin
Immunol 1981;68:15-9.

7 Barbee RA, Halonen M, Lebowitz MD, Burrows B. Distribution of IgE in a community population sample: correlations with age, sex and allergen skin test reactivity. J Allergy Clin Immunol 1981;68:106-11.

8 Burrows B, Halonen M, Barbee RA, Lebowitz MD. The relationship of serum immunoglobulin $\mathrm{E}$ to cigarette smoking. Am Rev Respir Dis 1981;124:523-5.

9 Halonen M, Barbee RA, Lebowitz MD, Burrows B. An epidemiological study of the interrelationships of total serum immunoglobulin E, allergy skin test reactivity, and eosinophilia. J Allergy Clin Immunol 1982;69: 221-8.

10 Barbee RA, Kaltenborn W, Lebowitz M, Burrows B. Longitudinal changes in allergen skin test reactivity in a community population sample. $J$ Allergy Clin Immunol 1987;79:16-24.

11 Barbee RA, Halonen M, Kaltenborn W, Lebowitz MD, Burrows B. A longitudinal study of serum $\operatorname{IgE}$ in a community cohort: correlations with age, sex, smoking, and atopic status. $J$ Allergy Clin Immunol 1987;79:919-27.

12 Taussig LM, Wright AL, Morgan WJ, Harrison HR, Ray CG, Group Health Medical Associates. The Tucson Children's Respiratory Study: 1. Design and implementation of a prospective study of acute and chronic respiratory illness in children. Am J Epidemiol (in press).

13 Halonen M, Dunn AM, Holberg CJ, Wright AL, Taussig LM. Total serum IgE in infants: relation to initial cord serum IgE level, age, gender and lower respiratory infections [abstract]. Am Rev Respir Dis 1985;131:A23.

14 Wittig HJ, Belloit J, De Fillippi I, Royal G. Age-related serum immunoglobulin $E$ levels in healthy subjects and in patients with allergic disease. $J$ Allergy Clin Immunol 1980;66:305-13.

15 Zetterstrom O, Osterman K, Machado L, Johansson 
SGO. Another smoking hazard: raised serum IgE concentration and increased risk of occupational asthma. Br Med J 1981;283:1215-7.

16 Chan-Yeung M, Lam S. State of Art: Occupational asthma. Am Rev Respir Dis 1986;133:686-703.

17 Chapman MD, Pollart SM, Luczynska CM, Platts-Mills TAE. Hidden allergic factors in the etiology of asthma. Chest 1988;94:185-90.
18 Kino T, Chihara J, Fukuda K, Sasaki Y, Shogaki Y, Oshima S. Allergy to insects in Japan III. High frequency of IgE antibody responses to insects (moth, butterfly, caddis fly, and chironomid) in patients with bronchial asthma and immunochemical quantitation of the insect-related airborne particles smaller than $10 \mathrm{fm}$ in diameter. $J$ Allergy Clin Immunol 1987;79: $857-66$. 